\title{
Apical sparing of longitudinal strain in speckle-tracking echocardiography
}

\section{A sensitive and specific finding in cardiac amyloidosis}

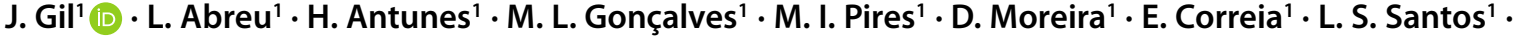 \\ J. C. Cabral ${ }^{1}$
}

Published online: 14 August 2018

(c) The Author(s) 2018

A 47-year-old man was admitted for acute heart failure. The ECG had low voltage criteria. Transthoracic echocardiogram showed bi-atrial dilation, left ventricular concentric hypertrophy with reduced ejection fraction (LVEF of 48\%) and hypertrophy of the right ventricular free wall. There was no valve dysfunction. Two-dimensional speckle-tracking echocardiography showed an apical sparing pattern of longitudinal strain (Fig. 1). Electrophoresis of serum proteins and bone marrow biopsy confirmed multiple myeloma. This suggested AL-type amyloidosis, and abdominal fat biopsy demonstrated amyloid-like, birefringent substance deposition in polarised light. Chemotherapy was started, remission occurred, and the patient remained stable after over 3 years of follow-up.

Amyloidosis is a multi-systemic disease characterised by the deposition of amyloid fibrils, cardiac involvement being usually associated with poor prognosis [1, 2]. Relative sparing of longitudinal strain in the left ventricular apex, which may be related to less amyloid deposition occurring in the apex than in the base, is highly sensitive and specific for the diagnosis of cardiac amyloidosis [1,2].

Conflict of interest J. Gil, L. Abreu, H. Antunes, M.L. Gonçalves, M.I. Pires, D. Moreira, E. Correia, L.S. Santos and J.C. Cabral declare that they have no competing interests.

Open Access This article is distributed under the terms of the Creative Commons Attribution 4.0 International License (http:// creativecommons.org/licenses/by/4.0/), which permits unrestricted use, distribution, and reproduction in any medium, provided you give appropriate credit to the original author(s) and the source, provide a link to the Creative Commons license, and indicate if changes were made.

\section{J. Gil}

juliogilpereira@gmail.com

1 Cardiology Department, Centro Hospitalar Tondela-Viseu, Viseu, Portugal

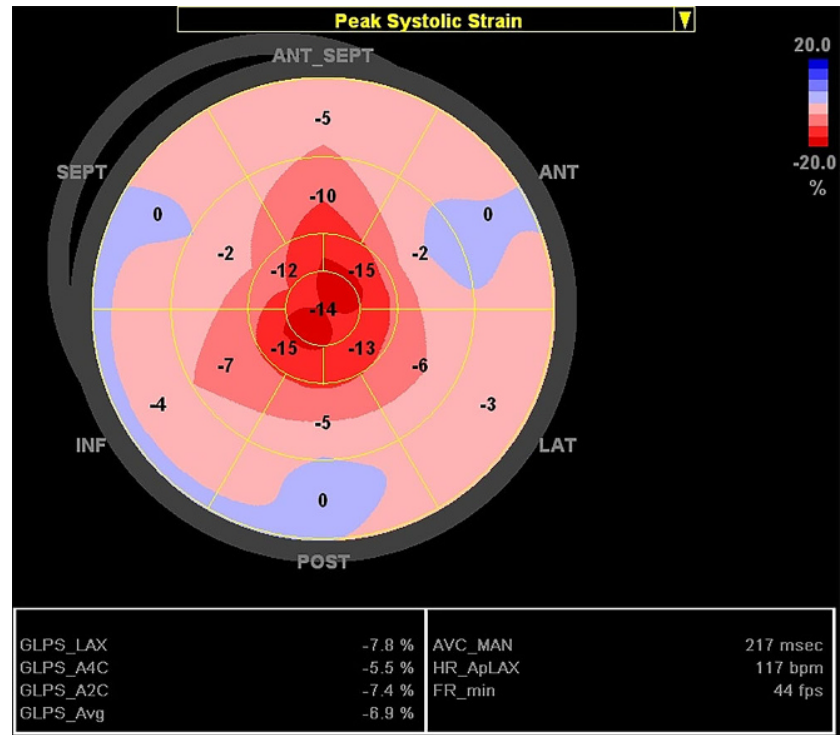

Fig. 1 Apical sparing of longitudinal strain (LS) in cardiac amyloidosis. Global LS was of $-6.9 \%$. The mean absolute values of LS in the apex, mid-cavity and basal section of the left ventricle were $-13.8,-5.3$ and $-2.0 \%$ respectively. Relative apical sparing is confirmed through the equation average apical LS/(average basal LS + mid-LS) [1], which in this patient resulted in a value of 1.89 . A value of over 1.0 is highly sensitive and specific for diagnosing cardiac amyloidosis when compared with other causes of left ventricular hypertrophy [1]

\section{References}

1. Phelan D, Collier P, Thavendiranathan P, et al. Relative apical sparing of longitudinal strain using two-dimensional speckle-tracking echocardiography is both sensitive and specific for the diagnosis of cardiac amyloidosis. Heart. 2012;98:1442-8.

2. Liu D, Hu K, Nordbeck P, Ertl G, Störk S, Weidemann F. Longitudinal strain bull's eye plot patterns in patients with cardiomyopathy and concentric left ventricular hypertrophy. Eur J Med Res. 2016;21:21. 